\title{
Erythrocyte Pyruvate Kinase Deficiency: A Kinetic Method for Differentiation Between Heterozygosity and Compound-Heterozygosity
}

\author{
Max Lakomek, Heinz Winkler, Sabine Linne, and Werner Schröter \\ Universitäts-Kinderklinik (M.L., S.L., W.S.) and Max-Planck-Institut für Biophysikalische Chemie, Göttingen (H.W.), \\ Federal Republic of Germany
}

\begin{abstract}
The goal of the present study was to search for criteria that allow one to distinguish between normal individuals and heterozygotes as well as compound heterozygotes for pyruvate kinase (PK) deficiency. As the residual activity of PK with heterozygotes was between $35 \%$ and $110 \%$ of the normal activity, it was necessary to find other methods to prove heterozygosity. The PK in the hemolysates of 23 patients suffering from PK deficiency, 36 paternal and maternal enzymes as well as the enzymes of five heterozygous and four normal siblings together with those of 20 normal individuals, were studied according to the recommendations of the International Committee for Standardization in Haematology. The following hematological and enzyme kinetic parameters can serve to identify heterozygotes for PK deficiency: 1) a slight reticulocytosis, 2) an up-to-twofold increase of the intracellular concentrations of glucose-6-phosphate in the erythrocyte, 3) a mixed cooperativity of the phosphoenolpyruvate (PEP)-binding process of PK, 4) a decreased nucleotide specificity with guanosine diphosphate and uridine diphosphate, and 5) a lowered affinity for adenosine diphosphate. The most significant criterium found with all heterozygotes was a mixed cooperativity of the PEP-binding process caused by the presence of a mixture of normal and mutant PK.
\end{abstract}

Key words: pyruvate kinase deficiency, enzyme kinetics, cooperative behaviour

\section{INTRODUCTION}

Deficiency of erythrocyte pyruvate kinase (ATP: pyruvate phosphotransferase E.C.2.7.1.40, PK) was first shown by Valentine et al. [1] to cause hereditary nonspherocytic hemolytic anemia. Apparently in most cases of PK deficiency mutant enzymes with abnormal characteristics are produced, whereas in the absence of consanguinity the majority of PK variants are considered to be compound-heterozygous for two mutant enzymes. These patients, as well as true homozygotes, show hemolytic anemia with different degrees of severity.

With a few exceptions, heterozygotes of PK deficiency are clinically and haematologically normal but often show slightly elevated levels of reticulocytes. The PK activity is between $35 \%$ and $110 \%$ of the normal value. Additionally, the intracellular concentrations of metabolites as ATP, 2,3-diphosphoglycerate (2,3-DPG) and glucose-6-phosphate (G-6-P) frequently are changed to some extent, compared to the normal values.
A recent publication standardizing techniques to characterize PK variants allows a comparison of results from different laboratories, as well as the identification of variants. Moreover, biochemical and clinical parameters can now be better correlated [2]. Recently we could demonstrate that chronic hemolysis is mainly caused by the loss of the allosteric properties of the mutant enzyme [3].

The goal of the present study was to find criteria so that one can distinguish between normal individuals and heterozygotes on the one hand and compound heterozygotes on the other hand. Biochemical and enzyme kinetic parameters together with the concentrations of some metabolites in the erythrocyte should serve as a tool for this purpose.

Received for publication August 22, 1988; accepted March 9, 1989

Address reprint requests to Prof. Dr. med. W. Schröter, UniversitätsKinderklinik, Robert-Koch-Str. 40, D-3400 Göttingen, FRG. 


\section{MATERIALS AND METHODS Subjects}

The PK was studied from the hemolysates of 23 patients suffering from PK deficiency, and from their 18 families consisting of 36 parents and five heterozygous siblings; the enzymes of four normal siblings were also studied.

The patients were 11 children aged $4-12$ years and 12 persons aged 17-30 years; five of the latter group were females. The parents were between 28 and 60 years old and were not related. The five heterozygous and the four normal siblings were between 8 and 24 years of age.

Twenty-two of the 41 heterozygotes examined were males; 18 of the 19 females were in the menstruation age group.

Twenty healthy students and technicians aged 20-27 years served as controls; eight of them were females.

\section{Reagents}

All reagents, substrates, and auxiliary enzymes were of the highest available purity and were purchased from Merck, Darmstadt, FRG, and Boehringer, Mannheim, FRG.

\section{Methods}

Routine hematological studies and the hemoglobin determination were performed by standard methods [4]. 2,3-DPG concentration was determined according to Ericson and de Verdier [5], whereas the concentrations of other internal phosphates - G-6-P, ATP, and ADPwere measured according to Minakami et al. [6]. In order to measure low concentrations reproducibly a sensitive Cary 218 photometer was used. A calibration curve was made with G-6-P concentrations varying between 0.01 and $0.3 \mu \mathrm{mol} / \mathrm{ml} \mathrm{RBC}$.

The method of Lowry et al. [7] was used with bovine serum albumin as a standard to measure the protein concentration. Hemolysate was prepared according to the method of Beutler et al. [8] and dialyzed prior to use. PK activity in the hemolysate was measured according to an optimized assay procedure (Lakomek et al.) [9] at 334 $\mathrm{nm}$ and $37^{\circ} \mathrm{C}$ using computerized Zeiss PMQ3 or Kontron 820 spectrophotometers connected online to a PDP11/44 computer. The assay composition was as follows (final concentrations in a total volume of $2.0 \mathrm{ml}$ ): $100 \mathrm{mmol} / 1$ iter triethanolamine $/ \mathrm{HCl} \quad 0.5 \mathrm{mmol} / \mathrm{liter}$ EDTA, pH 7.5; $5 \mathrm{mmol} / \mathrm{liter} \mathrm{MgCl}_{2} ; 30 \mathrm{mmol} /$ liter $\mathrm{KCl}$; $0.2 \mathrm{mmol} / \mathrm{liter} \mathrm{NADH} ; 6$ units lactate dehydrogenase $/ \mathrm{ml}$; $50 \mu \mathrm{l}$ enzyme solution. The phosphoenolpyruvate (PEP) concentration was varied between $0.025 \mathrm{mmol} / \mathrm{liter}$ and $5 \mathrm{mmol} / \mathrm{liter}$. This assay mixture was preincubated for 10 $\min$ at $37^{\circ} \mathrm{C}$. Reaction was initiated by addition of an
ADP solution of $\mathrm{pH} 7.5$, resulting in a final concentration of $1.5 \mathrm{mmol} /$ liter ADP.

For characterization of the PK, standard methods for the analysis of mutant enzymes, established by the International Committee for Standardization in Haematology [2], were used. The kinetic parameters $\left(\mathrm{V}_{\max }, \mathrm{K}_{0.5 \mathrm{~s}}\right)$ and the Hill coefficient $\left(\mathrm{n}_{\mathrm{H}}\right)$ were evaluated with the aid of a PDP1 1/44 or UNIVAC 1 100/82 computer. In case of hyperbolic reaction kinetics indicating noncooperative substrate binding behaviour (cf. Fig. 3), $V_{\max }$, and $K_{0.5 s}$ were obtained from computer plots according to the commonly used procedures of Lineweaver-Burk [10], Hanes [11], Eadie [12], and Hofstee et al. [13]; almost identical values resulted from all methods.

The parameter describing cooperativity $\left(\mathrm{n}_{\mathrm{H}}\right)$ was obtained from the well-known Hill plot, whereas a Scatchard plot [14] gave additional information about positive, negative, or mixed cooperativity.

A computer program especially designed by Wieker et al. [15] for the determination of kinetic parameters from sigmoidal steady-state kinetics was used to account correctly for complexities that arise with cooperative systems in order to evaluate the correct values of $V_{\max }$, $\mathrm{K}_{0.5 \mathrm{~s}}$ and the Hill coefficient. Based upon our earlier experience [16] we recommend that the substrate concentration be varied over a wide range below and above the $\mathrm{K}_{0.5 \mathrm{~S}}$ value and that the data be evaluated according to a procedure similar to that of Wieker et al. The Hill plot then results in an S-shaped curve, where the limiting slopes at vanishing and infinite substrate concentrations are 1.0. The true Hill coefficient has to be calculated from the slope at the midpoint of the curve ([S] = $\left[S_{0.5 s}\right]$, cf. Fig. 2). Similar precautions must be taken to describe cooperativity in terms of a Scatchard plot.

\section{RESULTS}

In 41 parents and heterozygous siblings of 23 patients suffering from PK deficiency the concentrations of internal phosphates were determined, and the mutant enzymes were biochemically characterized. A change of the regulatory properties of the PK was used to prove heterozygosity of the siblings.

The patients suffering from mild hemolysis without anemia showed a mean hemoglobin value of $14.8 \mathrm{~g} / \mathrm{dl}$ (hematocrit 45\%); those with mild anemia showed 10.2 $\mathrm{g} / \mathrm{dl}$ (hematocrit 31\%); and those with severe clinical course showed $7.5 \mathrm{~g} / \mathrm{dl}$ (hematocrit $22 \%$ ).

The heterozygotes were not clinically affected and exhibited normal hemoglobin concentrations $(14.5 \mathrm{~g} / \mathrm{dl})$ and hematocrit values $(44 \%)$. Females had a mean hemoglobin concentration of $13.9 \mathrm{~g} / \mathrm{dl}$, and males had a mean of $15.2 \mathrm{~g} / \mathrm{dl}$, independent of their age. No het- 
TABLE I. Count of Reticulocytes, Concentrations of G-6-P, 2,3-DPG, and PK Activity in Red Blood Cells of Heterozygotes and Compound Heterozygotes

\begin{tabular}{|c|c|c|c|}
\hline \multirow[b]{2}{*}{$\begin{array}{l}\text { Biochemical } \\
\text { data }\end{array}$} & \multicolumn{2}{|c|}{ Probands } & \multirow[b]{2}{*}{$\begin{array}{r}\text { Controls } \\
(\mathrm{n}=20)\end{array}$} \\
\hline & $\begin{array}{l}\text { Heterozygote } \\
\qquad(n=41)\end{array}$ & $\begin{array}{l}\text { Compound } \\
\text { heterozygote } \\
(\mathrm{n}=23)\end{array}$ & \\
\hline \multicolumn{4}{|l|}{ Reticulocytes (\%) } \\
\hline $0.5-1.5$ & $4 / 41$ & - & $20 / 20$ \\
\hline $1.6-4.5$ & $37 / 41$ & $4 / 23$ & - \\
\hline$>5.0$ & - & $19 / 23$ & - \\
\hline \multicolumn{4}{|c|}{ 2.3-DPG $(\mu \mathrm{mol} / \mathrm{ml} \mathrm{RBC})$} \\
\hline $\begin{array}{l}4.2-5.3 \\
\text { (mean value } \\
4.75 \pm 0.55 \text { ) }\end{array}$ & $29 / 41$ & $4 / 23$ & $20 / 20$ \\
\hline $5.4-7.15$ & $12 / 41$ & $6 / 23$ & - \\
\hline$>7.15$ & - & $13 / 23$ & - \\
\hline \multicolumn{4}{|c|}{ G-6-P $(\mu \mathrm{mol} / \mathrm{ml} \mathrm{RBC})$} \\
\hline $\begin{array}{l}0.026-0.043 \\
\text { (mean value } \\
0.0345 \pm 0.0085)\end{array}$ & $8 / 41$ & $3 / 21$ & $20 / 20$ \\
\hline $0.044-0.069$ & $33 / 41$ & $5 / 23$ & - \\
\hline$>0.069$ & - & $15 / 23$ & - \\
\hline \multicolumn{4}{|c|}{ PK activity (\% of normal activity) } \\
\hline $0-25$ & - & $3 / 23$ & - \\
\hline $26-50$ & $1 / 41$ & $9 / 23$ & - \\
\hline $51-85$ & $33 / 41$ & $5 / 23$ & - \\
\hline $86-115$ & $7 / 41$ & $4 / 23$ & $20 / 20$ \\
\hline$>115$ & - & $2 / 23$ & - \\
\hline
\end{tabular}

erozygous proband was anemic from other causes, and there was no increase of indirect bilirubin concentrations indicating hemolysis in this subjects. In Table I, reticulocyte counts, substrate concentrations, and PK activity obtained with heterozygotes are compared with those of compound heterozygotes and normal individuals.

As presented in Table I only four heterozygotes showed a normal number of reticulocytes $(0.5-1.5 \%)$, whereas 37 exhibited elevated reticulocyte counts between $1.6 \%$ and $4.5 \%$ (mean value $2.7 \pm 0.83 \mathrm{SD}$ ). The level of 2,3-DPG was elevated in about $30 \%$ of the heterozygotes up to 1.5 -fold $(7.15 \mu \mathrm{mol} / \mathrm{ml}$ red blood cells), whereas G-6-P concentrations were increased in $80 \%$ of the heterozygotes up to twofold compared to the controls. The internal ATP and ADP concentrations of the red blood cells deviated only slightly from the normal values and, therefore, are not given in this table. As shown in Table I, and more evidently in Figure 1, the PK activity of the majority of the heterozygotes was between $50 \%$ and $85 \%$ of the normal activity; in only one case $35 \%$ activity was found, whereas seven probands showed normal values. Concerning the patients with PK deficiency approximately $30 \%$ had a relatively high residual enzyme activity of more than $100 \%$.

Alterations of the regulatory properties of PK are the best biochemical criteria to distinguish between the en- zymes of normal individuals, heterozygotes, and compound-heterozygotes. Normal PK shows a positive cooperative behaviour during substrate binding and therefore exhibits the characteristic features of an allosteric enzyme as given in Figure 2. The Michaelis-Menten plot shows a sigmoidal curve, i.e., a weak activity at low substrate level, which rapidly increases at substrate concentrations around the $\mathrm{K}_{0.5 \mathrm{~s}}$ value. At higher substrate concentrations the curve levels off. Irrespective of the plotting method (Lineweaver-Burk, Hanes, and EadieHofstee) for determination of $\mathrm{K}_{0.5 \mathrm{~S}}$ and $\mathrm{V}_{\max }$, essentially identical results were obtained. The cooperativity parameters $\left(\mathrm{n}_{\mathrm{H}}\right)$ were evaluated from the Hill and Scatchard plots.

The mutant enzymes-the so-called PK variants - however, have lost or changed their allosteric regulation, exhibiting noncooperativity (Fig. 3) or negative cooperativity (Fig. 4) as evidenced by hyperbolic Michaelis-Menten plots $[3,16]$. In contrast to the kinetic behaviour found with normal individuals and compound heterozygotes, the enzymes of the heterozygotes studied so far showed a mixed cooperative substrate binding with positive cooperativity at low substrate concentrations and negative cooperativity at high substrate level (Fig. 5). This indicates a mixture of normal and defective enzymes and becomes evident in all reaction kinetic plots with the exception of the Michaelis-Menten plots. In the Hill plot there is a region where the negative and positive part of the curve overlap as a consequence of the mixed cooperativity.

The Hill coefficients $\left(\mathrm{n}_{\mathrm{H}}=1.2-2\right)$ as given in Table II are calculated assuming of a predominant positive cooperative substrate binding mechanism and are compared with those of the compound heterozygotes and the controls. In Table II the most important enzyme kinetic data obtained with the controls, the compound heterozygotes, and the heterozygotes are summarized. Eighty percent of the heterozygotes show a normal affinity of PK to the substrate phosphoenolpyruvate (PEP), whereas the remaining $20 \%$ show a lowered $\mathrm{K}_{0.5 \mathrm{~s}} \mathrm{PEP}$, indicating higher affinity. In contrast to this finding, $80 \%$ exhibit a decreased affinity for the cosubstrate ADP, but in some cases a normal or increased affinity for ADP was observed. With respect to the nucleotide specificity all the heterozygotes showed a normal enzyme activity with cytidine diphosphate (CDP); the activity with guanosine (GDP) diphosphate and uridine diphosphate (UDP), however, was decreased in $90 \%$ of all cases. Compared to ADP the PK activity with GDP and UDP was lowered to $30-50 \%$ and $40-60 \%$, respectively.

Thermostability and temperature of denaturation of the mixture of isoenzymes of the heterozygotes are not given in this table. The thermostability (incubating the PK for $60 \mathrm{~min}$ at $53^{\circ} \mathrm{C}$ ) was reduced in $50 \%$ of the cases. With 


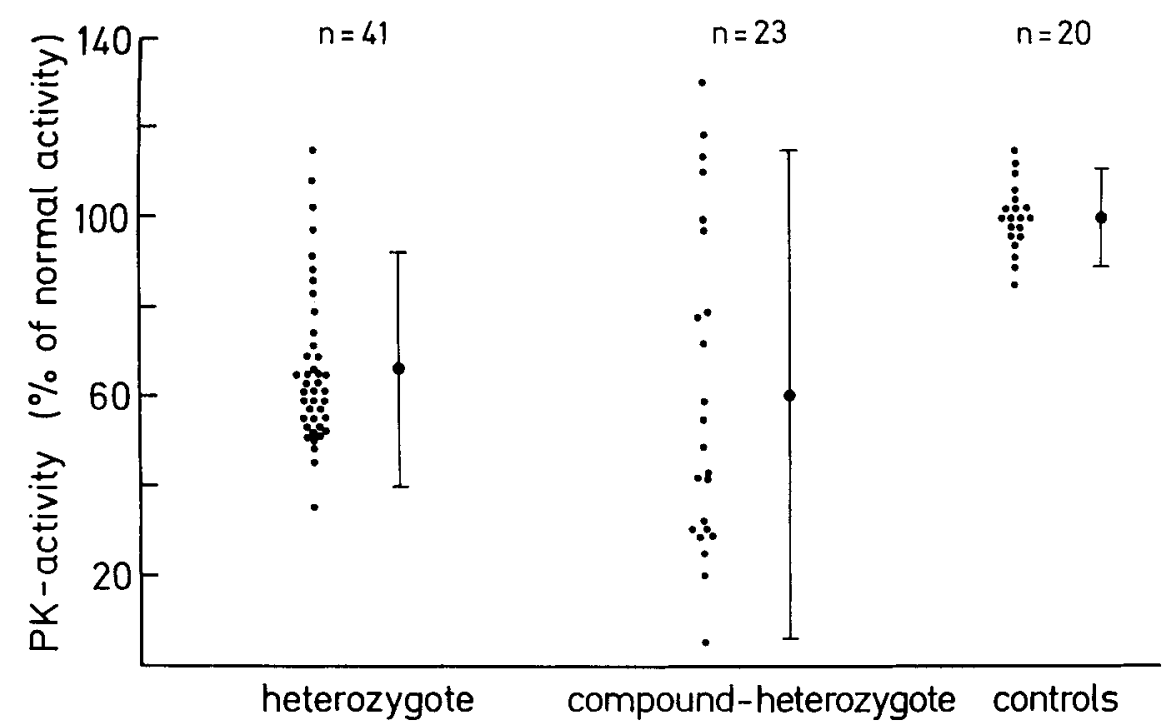

Fig. 1. RBC-PK activity of heterozygotes and compound heterozygotes. Determination as mean values ( \pm 1.5 S.D.).


Fig. 2. Example for a positive cooperative substrate binding process as found in normal PK. Different reaction kinetic plots for determination of $V_{\max }, K_{0.55}$, and Hill-coefficient. a: Michaelis-Menten plot. b: Eadie-Hofstee plot. c: Scatchard plot. d: Hill plot.

respect to the temperature of denaturation, $60 \%$ of the enzymes showed a higher value than the normal enzymes, whereas $40 \%$ denature within the normal temperature range (i.e., $53-68^{\circ} \mathrm{C}$ ). However, there was no correlation between the thermostability at $53^{\circ} \mathrm{C}$ and the temperature of denaturation; i.e., enzymes with increased temperature of denaturation did not necessarily exhibit alterations in the thermostability. 


\section{DISCUSSION}

For the diagnosis of heterozygosity for PK deficiency the residual enzyme activity alone is only of limited value (cf. Fig. 1). The relatively high PK activity values occasionally found in one-half of the patients and in many heterozygotes can be explained by increased reticulocyte counts; the reticulocyte PK has been reported to exhibit a much higher activity than the erythrocyte enzyme [17-19]. The following list of haematological and kinetic parameters can be used to identify the enzymes of heterozygotes:

1. Slight reticulocytosis (up to $5 \%$ reticulocytes)

2. Up to twofold increase of the intracellular concentrations of G-6-P

3. Mixed cooperativity of PK during PEP-binding

4. Decreased nucleotide specificity with GDP and UDP

5. Lowered affinity for ADP

The two most remarkable haematological alterations with heterozygotes were a slight reticulocytosis observable with $90 \%$ of the probands and up to a twofold in-

TABLE II. Enzyme Kinetic Data of Heterozygotes and Compound Heterozygotes

\begin{tabular}{|c|c|c|c|}
\hline \multirow[b]{2}{*}{$\begin{array}{l}\text { Biochemical } \\
\text { data }\end{array}$} & \multicolumn{2}{|c|}{ Probands } & \multirow[b]{2}{*}{$\begin{array}{l}\text { Controls } \\
(\mathrm{n}=20)\end{array}$} \\
\hline & $\begin{array}{l}\text { Heterozygote } \\
\qquad(\mathrm{n}=41)\end{array}$ & $\begin{array}{l}\text { Compound } \\
\text { heterozygote } \\
(\mathrm{n}=23)\end{array}$ & \\
\hline Hill-coefficient $\left(\mathrm{n}_{\mathrm{H}}\right)$ & $(1.2-2)$ & $0.64-1.11$ & $1.45-2.15$ \\
\hline \multicolumn{4}{|l|}{ Kinetic behaviour } \\
\hline Pos. cooperative & - & - & $20 / 20$ \\
\hline Mixed cooperative & $41 / 41$ & $5 / 23$ & 一 \\
\hline Noncooperative & 一 & $16 / 23$ & - \\
\hline Negative cooperative & - & $2 / 23$ & - \\
\hline \multicolumn{4}{|l|}{$\mathrm{K}_{0.5 \mathrm{~s}} \mathrm{PEP}$ (mmol/liter) } \\
\hline$<0.40$ & $8 / 41$ & $13 / 23$ & - \\
\hline $0.40-1.20$ & $33 / 41$ & $8 / 23$ & $20 / 20$ \\
\hline$>1.20$ & - & $2 / 23$ & - \\
\hline \multicolumn{4}{|l|}{$\mathrm{K}_{0.5 \mathrm{~s}} \mathrm{ADP}(\mathrm{mmol} / \mathrm{liter})$} \\
\hline$<0.12$ & $1 / 41$ & $2 / 23$ & $一$ \\
\hline $0.12-0.22$ & $8 / 41$ & $2 / 23$ & $20 / 20$ \\
\hline$>0.22$ & $32 / 41$ & $19 / 23$ & - \\
\hline \multicolumn{4}{|c|}{$\begin{array}{l}\text { Nucleotide specificity } \\
\text { (\% of activity with ADP) }\end{array}$} \\
\hline \multicolumn{4}{|l|}{ CDP } \\
\hline $2-9$ & $41 / 41$ & $20 / 23$ & $20 / 20$ \\
\hline$>9$ & - & $3 / 23$ & - \\
\hline \multicolumn{4}{|l|}{ GPD } \\
\hline$<61.5$ & $37 / 41$ & $18 / 23$ & - \\
\hline $61.5-83$ & $4 / 41$ & $4 / 23$ & $20 / 20$ \\
\hline$>83$ & - & $1 / 23$ & - \\
\hline \multicolumn{4}{|l|}{ UDP } \\
\hline $63-81.5$ & $7 / 41$ & $3 / 23$ & $20 / 20$ \\
\hline $40-62$ & $37 / 41$ & $13 / 23$ & - \\
\hline $24-39$ & 一 & $7 / 23$ & - \\
\hline
\end{tabular}

crease of G-6-P concentration in the red blood cells in $80 \%$ of the probands.

The most important biochemical parameter found with all heterozygotes was mixed cooperativity of the PK during substrate binding caused by the presence of a mixture of normal and mutant enzyme. At low substrate concentrations the mixture of isoenzymes exhibits positive cooperativity, whereas at high substrate concentrations negative cooperative binding behaviour predominates; this results in an "over-all" Hill coefficient between 1.2 and 2.0, which is rather problematic as it certainly does not describe a single elementary binding process. However, it has to be emphasized that mixed cooperative substrate binding can also occur in case of compound heterozygotes. We could show previously [20] that the reticulocyte PK of patients suffering from PK deficiency shows positive cooperative behaviour of the PEP binding, and its activity is higher than that of the erythrocyte PK. If the number of reticulocytes increases to $20-30 \%$ in a red blood cell suspension - this occurs mainly with splenectomized patients-mixed cooperative behaviour would also be observed, but in this case it would be due to a mixture of the reticulocyte PK (positive cooperative) and the defective erythrocyte PK (non- or negative cooperative).

With about $90 \%$ of the heterozygotes the enzyme activity of the PK with the nucleotides GDP and UDP was less than normal, and in $80 \%$ of the cases the affinity for its cosubstrate ADP was decreased.

These five criteria not only allow an unambigous diagnosis of heterozygosity for PK deficiency but in most cases also prove the occurrence of a PK variant-without the extensive biochemical characterization according to the recommendations of the International Committee for Standardization in Haematology [2]. With the aid of these five criteria, together with the determination of the enzyme activity, we are able to solve the following diagnostic problems:

1. Determine whether a heterozygosity exists with the siblings of the patients.

2. Determine a PK deficiency with patients suffering from congenital hemolytic anemia, where determination of the osmotic fragility, hemoglobin electrophoresis, and erythrocyte enzyme activities alone do not allow a clear diagnosis of the disease.

3. PK deficiency can now be determined in cases of splenectomized patients where splenectomy had been performed in the past without having the correct diagnosis for PK deficiency. This can be achieved either by showing heterozygosity with the parents or, in the case of the patient alone, by demonstration of a mixed cooperative behaviour of the PK, caused by the presence of a reticulocyte and erythrocyte enzyme. 

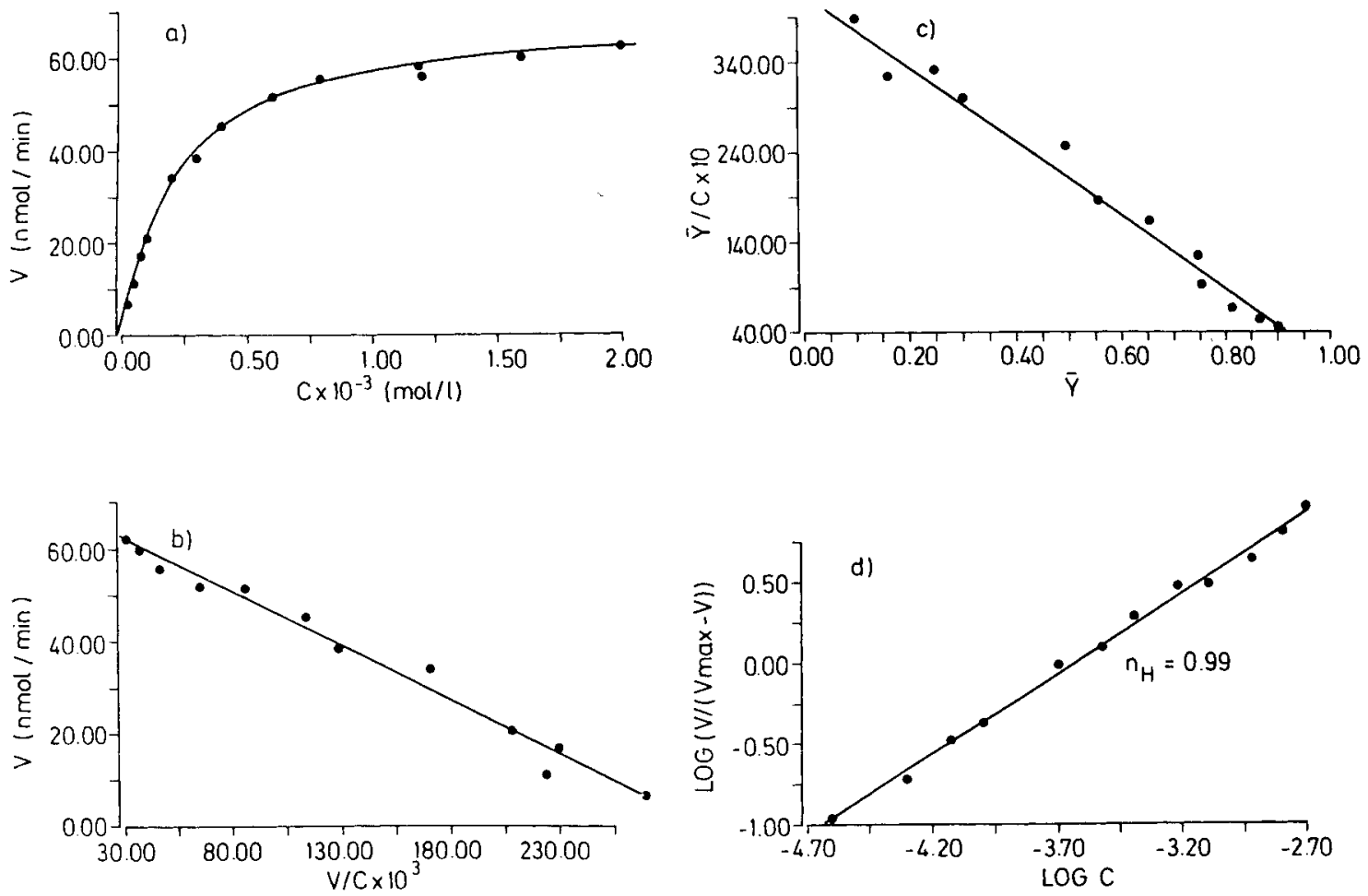

Fig. 3. Noncooperative substrate binding of a defective RBC-PK. a: Michaelis-Menten plot. b: Eadie-Hofstee plot. c: Scatchard Plot. d: Hill plot.
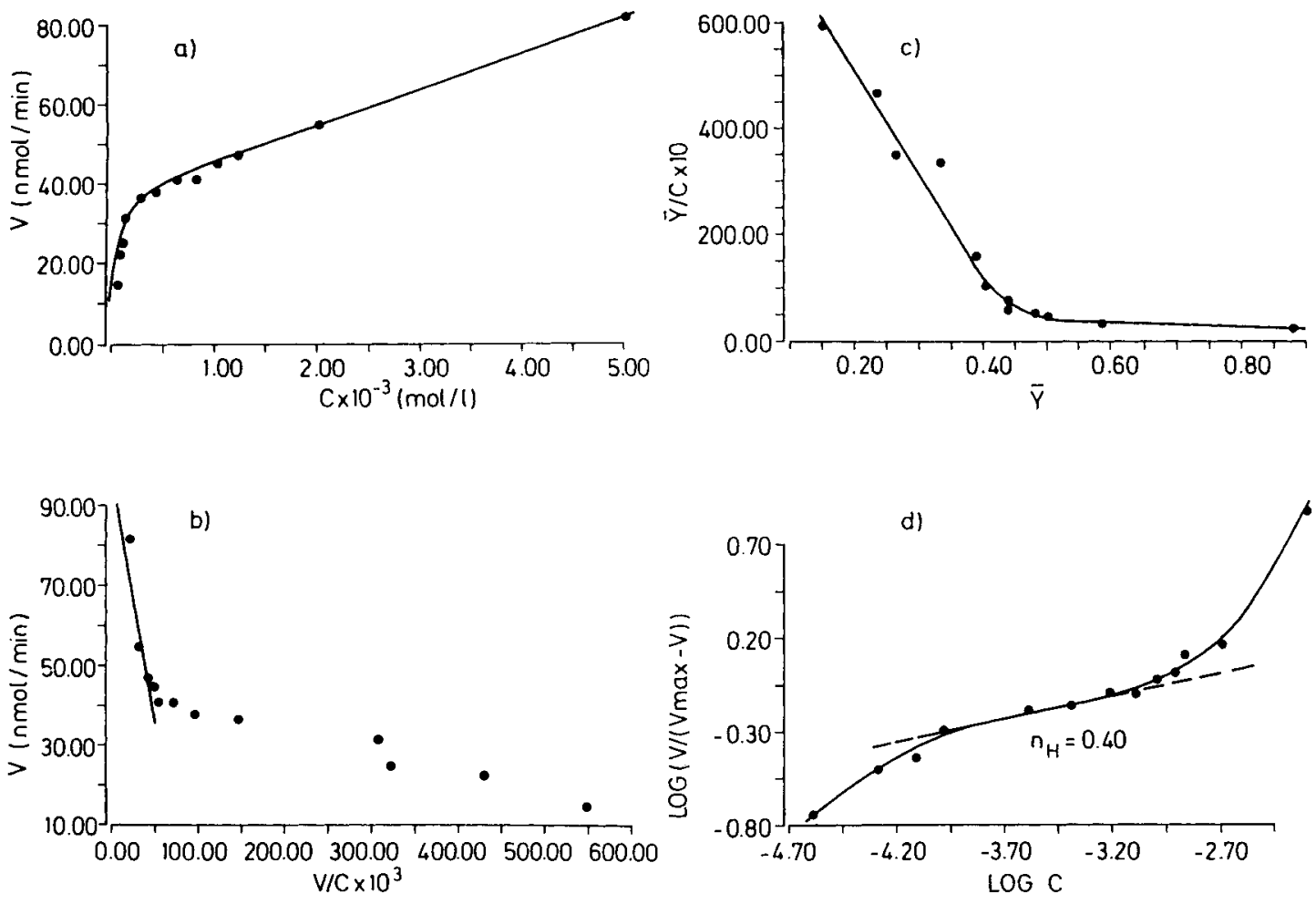

Fig. 4. Negative cooperative substrate binding of a defective RBC-PK. a: MichaelisMenten plot. b: Eadie-Hofstee plot. c: Scatchard plot. d: Hill plot. 

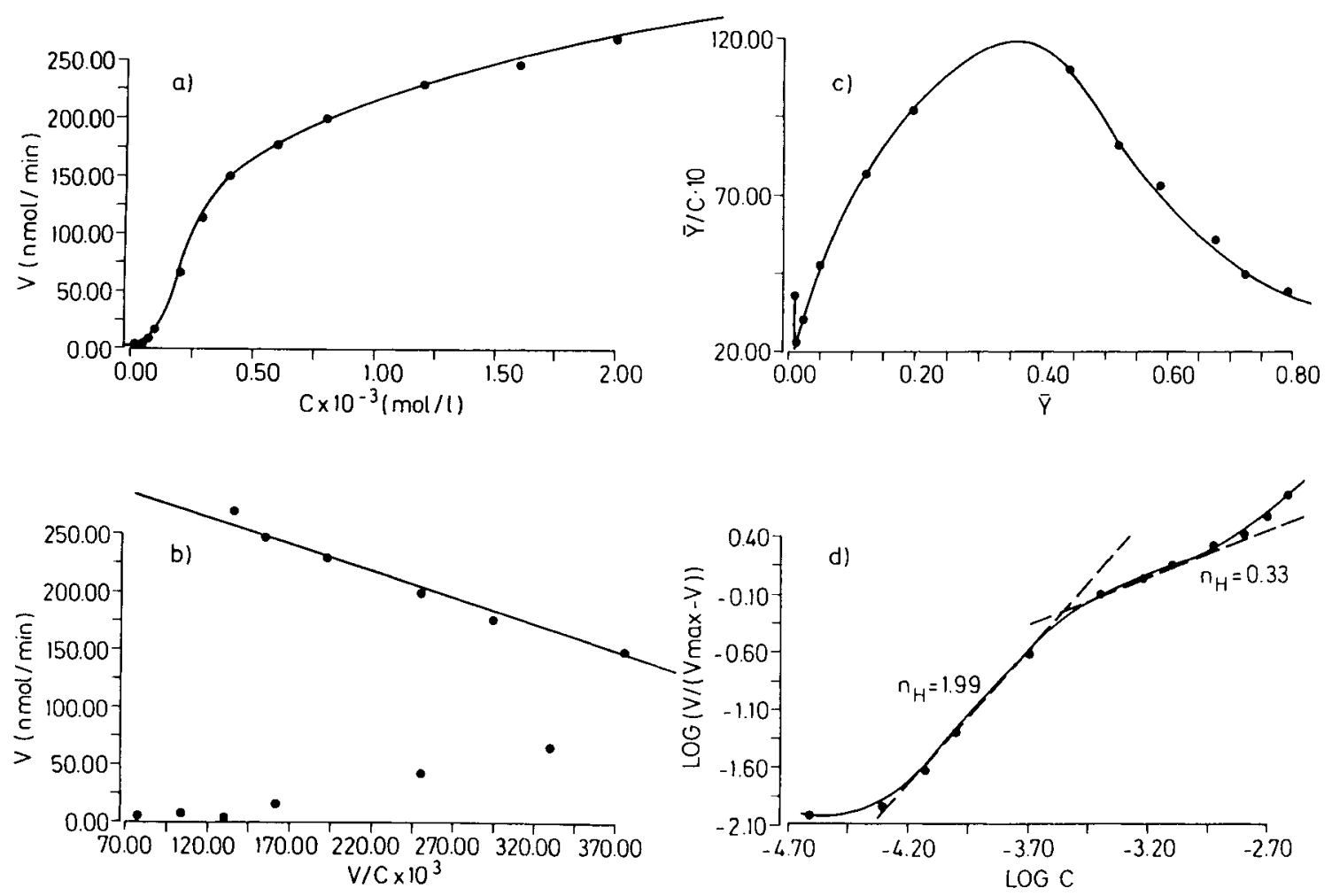

Fig. 5. Mixed cooperative substrate binding arising from a mixture of normal RBC-PK and an abnormal isoenzyme. a: Michaelis-Menten plot. b: Eadie-Hofstee plot. c: Scatchard plot. d: Hill plot.

4. For evidencing compound-heterozygosity for PK deficiency the studies have always to be extended to the parental enzymes. Only if one succeeds in demonstrating a mutant PK besides the normal paternal and maternal enzyme can one assume that the patient carries the genes for two different anomal PK allels.

\section{ACKNOWLEDGMENTS}

Part of this work was performed by S. Linne in partial fulfillment of the requirements for the MD degree of the University of Göttingen, 1987. The authors gratefully acknowledge the technical contributions of Ingrid Botta and Gabriele Heinrich. They also thank Burga Huning for typing and Dr. Robert W. Clegg for reading this manuscript. These studies were supported by the Deutsche Forschungsgemeinschaft, Bonn-Bad Godesberg, La $527 / 1$.

\section{REFERENCES}

1. Valentine WN, Tanaka KR, Miwa S: A specific erythrocyte glycolytic enzyme defect (pyruvate kinase) in three subjects with congenital non-spherocytic hemolytic anemia. Trans Assoc Am Physicians 74: $100-110,1961$.
2. International Committee for Standardization in Haematology: Recommended methods for the characterization of red cell pyruvate kinase variants. Br J Haematol 43:275-286, 1979.

3. Schröter W, Lakomek M, Scharnetzky M, Tillmann W, Winkler H: Pyruvate kinase "Göttingen ${ }_{1,2}$ ": Congenital hemolytic anemia, evidence of double heterozygosity, and lack of enzyme cooperativity. Hum Genet 60:381--386, 1982.

4. Dacie JV, Lewis SM: "Practical Haematology," 5th edn. Edingburgh: Churchill Livingstone, 1975.

5. Ericson $\mathrm{H}$, Verdier de $\mathrm{CH}$ : Modified method for the determination of 2.3-diphosphoglycerate in erythrocytes. Scand J Clin Lab Invest 29: 85-90, 1972.

6. Minakami S, Suzuki C, Saito T, Yoshikawa H: Studies on erythrocyte glycolysis. I. Determination of the glycolytic intermediates in human erythrocytes. J Biochem (Tokyo) 58:543-549, 1965.

7. Lowry OH, Rosebrough NJ, Farr AL, Randall RJ: Protein measurement with the folin phenol reagent. J Biol Chem 193:265-275, 1951.

8. Beutler E, Blume KG, Kaplan JC, Löhr GW, Ramot B, Valentine WN: International Committee for Standardization in Haematology: Recommended methods for red-cell enzyme analysis. Br J Haematol 35:331-340, 1977.

9. Lakomek M, Schröter W, Winkler H: Red cell pyruvate kinase deficiency: An optimised assay. Clin Chim Acta 108:31-40, 1980.

10. Lineweaver $\mathrm{H}$, Burke D: The determination of enzyme dissociation constants. J Am Chem Soc 56:658-666, 1934.

11. Hanes CS: Studies on plant amylases. I. The effect of starch concentration upon the velocity of hydrolysis by the amylase of germinated barley. Biochem J 26:1406-1421, 1932. 
12. Eadie GS: The inhibition of cholinesterase by physostigmine and prostigmine. J Biol Chem 146:85-93, 1942.

13. Hofstee BH, Dixon M, Webb EC: Non-inverted versus inverted plots in enzyme kinetics. Nature 184:1296-1298, 1958.

14. Scatchard G: The attractions of proteins for small molecules and ions. Ann NY Acad Sci 51:660-672, 1949.

15. Wieker $\mathrm{HJ}$, Johannes $\mathrm{KJ}$, Hess B: A computer program for the determination of kinetic parameters from sigmoidal steady state kinetics. FEBS Lett 8:178-185, 1970.

16. Lakomek M, Winkler H, Scharnetzky M, Tillmann W, Laier G, Marti HR, Schröter W: Erythrocyte pyruvate kinase deficiency: Characterization of a new variant (PK "Aarau"). Blut 48:123-129, 1984.
17. Beutler E: How do red cell enzymes age? Hypothesis and facts. Br J Haematol 64:408-409, 1986.

18. Jansen G, Koendermann L, Rijksen G, Cats BP, Staal GEJ: Characteristics of hexokinase, pyruvate kinase, and glucose-6-phosphate dehydrogenase during adult and neonatal reticulocyte maturation. Am J Hematol 20:203-215, 1985.

19. Piomelli S, Seaman C, Corash L: How do red cell enzymes age? Hypothesis and facts. Br J Haematol 64:407-408, 1986.

20. Lakomek M, Winkler H, Scharnetzky M, Tillmann W, Schröter W: Pyruvatkinase-Mangel des Erythrozyten: Kinetische und elektrophoretische Hinweise für eine posttranslationale Reifungsstörung. Onkologie 6:256, 1983. 